Postgrad. MEd. J. (1966), 42, 30

\title{
THE INFECTED OVARIAN CYST
}

\author{
A. E. R. BuCKLE, F.R.C.S., M.R.C.O.G. \\ Consultant, Department of Obstetrics and Gynaecology, Lewisham General Hospital, London, S.E.13.
}

Amongst the complications to which the ovarian cyst is heir, that of infection is nowadays infrequently encountered. The condition was well known to authors in the latter part of the nineteenth and early part of the present century and clinico-pathological details have been recorded by Cumston (1899), Watkins (1902), Peterson (1902) and Coe (1906). It is probable that the more frequent occurrence of acute bacterial septicaemia and the management of ovarian cysts by trans-abdominal puncture and aspiration were responsible factors and that, with the elective surgical management of ovarian cysts, infection as a complication has become more rare.

Later publications have centred mainly on isolated cases of infection of ovarian cysts by specific bacterial agents such as the typhoid bacillus (Lewis and LeConte, 1902; Walker, 1902; Taylor, 1907; Sutton, 1913), the paratyphoid bacillus (Corscaden, 1923; Bojesen, 1932; Staemmler, 1950), the gonococcus (Brettauer, 1908) and the tubercle bacillus (Forgue and Chauvin, 1919). Infection of an ovarian cyst during pregnancy has also been recorded (Baydoun and Sarram, 1961).

Although rare, the condition continues to be encountered and the purpose of this paper is to present the clinico-pathological details of a series of 12 cases encountered at Lewisham General Hospital between the years 1950-1964 inclusive. During this 15-year period, 775 cases of ovarian tumour (595 benign and 179 malignant) were admitted to the hospital, so that the incidence of infection was $1.55 \%$ of all ovarian tumours. As there was no evidence clinically or histologically of malignant change in the 12 cases under review, the incidence of infection in relation to non-malignant ovarian tumours was $2 \%$.

\section{Clinical Features}

\section{Age}

The ages of the patients are shown in Table 1. The youngest patient was aged 26 years and the oldest 75 years, the average age being 43 years.

\section{Relation to the menopause}

Nine of the 12 patients were premenopausal. Of the 3 post-menopausal patients, infection of the ovarian cyst followed vaginal surgery in one case and followed trans-abdominal aspiration in another case.

\section{Relation to pregnancy}

Symptoms followed term-delivery in 3 cases, although the interval between delivery and the time of diagnosis varied between the wide limits of 1 week and 24 weeks. In one case, symptoms followed an abortion at 8 weeks, the cyst being discovered on examination under anaesthesia at the time of evacuation of retained products of conception.

\section{Duration of symptoms}

This was very variable, the shortest being 24 hours and the longest 20 weeks, the average duration being 46 days.

\section{Presenting symptoms}

These are listed in Table 1 . The most frequent were abdominal pain ( 8 cases), pyrexia (4 cases), loss of weight ( 3 cases), general malaise ( 3 cases), abdominal enlargement ( 2 cases) and anorexia ( 2 cases). Other symptoms were nausea, vomiting, diarrhoea, irregular vaginal bleeding and dyspareunia.

\section{Relevant clinical findings}

All but one of the cases were febrile at the time of admission, the individual first readings varying between $37.2^{\circ} \mathrm{C} \quad\left(99^{\circ} \mathrm{F}\right)$ and $39^{\circ} \mathrm{C}$ $\left(102^{\circ} \mathrm{F}\right)$. The remaining patient was afebrile on admission but developed a swinging pyrexia after trans-abdominal aspiration for a presumed diagnosis of ascites. In all cases an abdominal or pelvic mass was present although in the case just mentioned the mass was only palpable after reduction in size of the cyst following trans-abdominal aspiration.

\section{Haematological findings}

The total white cell count and percentage of polymorphonuclear leucocytes found in each case at the time of admission are shown in Table 2 . In case 1 there was, in addition, a 
profound degree of anaemia (haemoglobin $4 \mathrm{~g}$./ $100 \mathrm{ml}$.). Though anaemia was present in several other of the cases, it was of minor degree.

It can be seen that the total white count was frequently normal despite the presence in the body of an encysted collection of pus.

\section{Operative findings}

These are outlined in Table 1, from which it may be seen that the cyst involved the left ovary in 10 cases and the right ovary in the remaining two cases. As will be mentioned later, tubal involvement consisted of oedema, often gross, without active endosalpingitis.

In all cases the cyst was found to have a grossly thickened wall and was usually adherent to surrounding structures, namely the pelvic side wall and uterus and was frequently covered by a grossly oedematous pelvic colon and mesocolon; small bowel was frequently found adherent to the infected cyst. Free fluid was usually present in the pelvis but in no instance had rupture of the cyst occurred prior to operation.

The operative procedures performed are also shown in Table 1.

\section{Post-operative management}

In those cases where there was considerable small-bowel adhesion to the infected cyst, continuous gastric suction and intravenous fluids were commenced after operation and continued until the bowel sounds returned. Drainage to the pelvis was employed on one occasion only (case 11).

Antibiotics were given in all cases after operation, pending precise bacteriological identification of the offending organism.

\section{Bacteriological findings}

These are shown in Table 3, from which it may be seen that a wide range of pathogenic bacteria were isolated. A similar wide range of organisms found in infected ovarian cysts was reported by Burger (1925).

It is of interest that the only case in the present series from which staphylococcus pyogenes was cultured was case 4, where symptoms followed trans-abdominal aspiration of the cyst.

\section{Pathological features}

These are shown in Table 4. In 7 cases, infection led to complete destruction of the cyst lining, making histological identification impossible. Of the 5 remaining cases, 3 were infected serous cystadenomata and 2 were infected benign teratomata. Tubal histology showed secondary tubal involvement from proximity but no evidence of acute endosalpingitis.

In two cases, appendicular histology showed low grade infection (cases 1 and 6).

Mortality and follow-up

There were no deaths in the 12 cases in this series. One patient (case 12) developed jaundice after operation and, as the organism isolated from the cyst contents on this occasion was the $\beta$-haemolytic streptococcus, it was thought that the jaundice followed severe bacterial infection. The condition cleared within four days and the patient thereafter had an uninterrupted recovery.

One patient (case 5) has had a further uneventful pregnancy resulting in term-delivery of a live male infant. Post-partum ligation of the remaining tube was performed and the pelvis noted to be clear of adhesions at this time.

\section{Discussion}

It is possible for an ovarian cyst to become infected by a variety of routes:

1. Introduction of infection at the time of abdominal aspiration or by needle aspiration through the posterior vaginal fornix.

2. Blood-borne infection during the course of acute bacterial septicaemia.

3. Lymphatic spread of infection from the post-partum or post-abortal uterus.

4. Following tubal infection.

5. From adherent bowel or appendix.

6. Following vaginal plastic surgery.

7. Following torsion of the pedicle of the cyst. Whilst infection of an ovarian cyst is rare, recurrent attacks of infection of ovary and tube, leading to the formation of a tubo-ovarian abscess, are more common. In the latter condition, the tube and ovary become intimately bound together in the formation of the wall of the abscess and it is frequently impossible to identify them separately; in the former condition, however, although the tube shares in the surrounding oedema, it is separately identifiable and shows no evidence of active endosalpingitis.

The infected ovarian cyst shows considerable increase in thickness of the wall and is filled with purulent material, the cyst lining being frequently represented by a layer of fibrin. The external surface may be affected by partial desquamation, leading to bowel adhesion (Cumston, 1899). Because of the frequent destruction of the lining epithelium, precise histological identification may be impossible so that it will be difficult to say whether one variety of cyst is more liable to this complication 


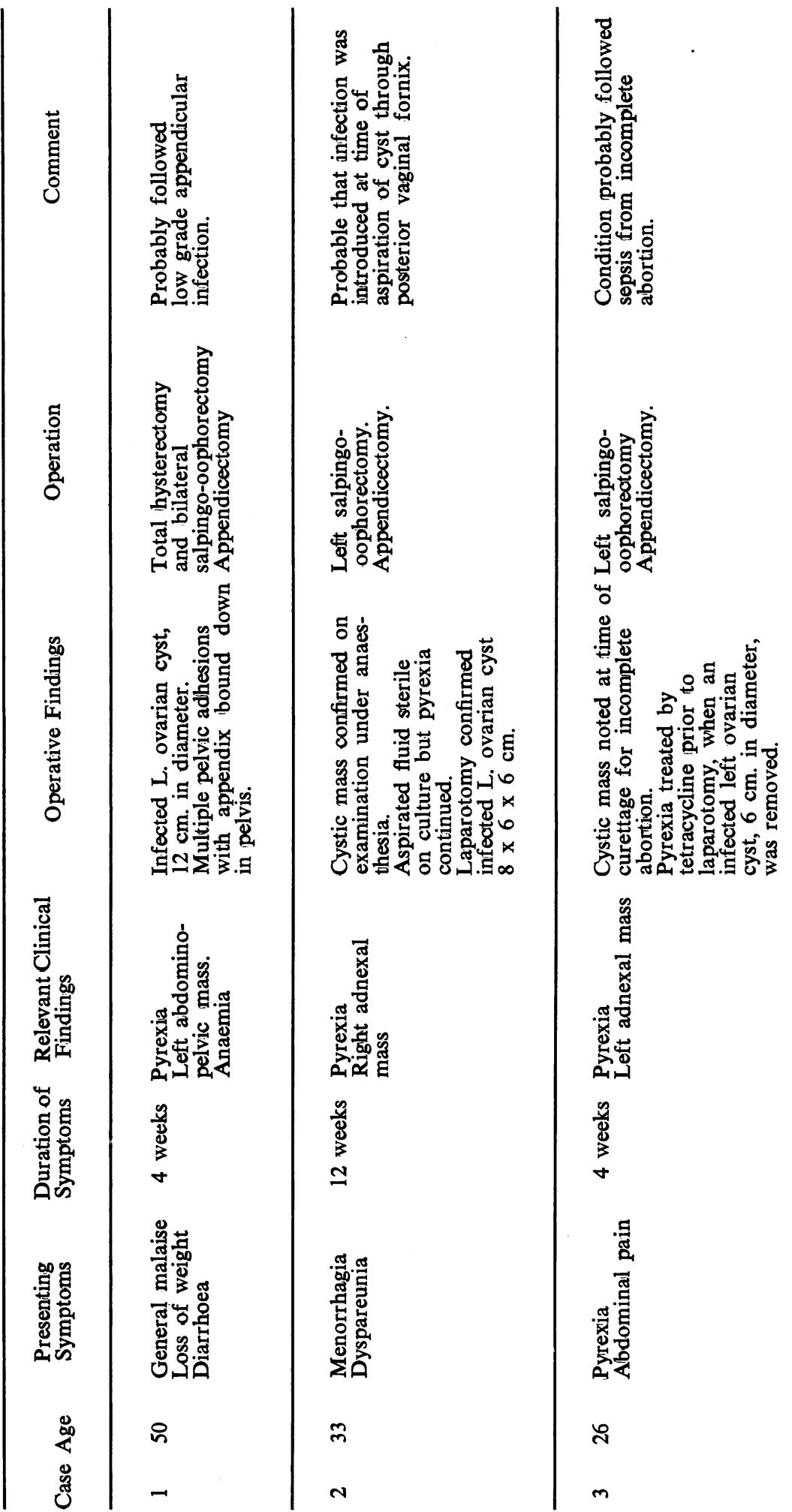

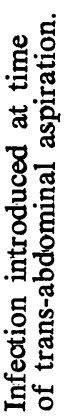

(1) 
@̊

范落

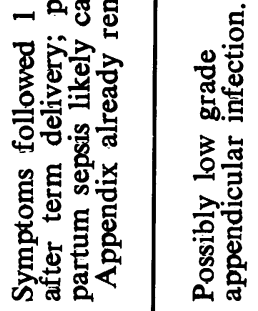

客㻤

둥혀

중

.

喜.

.90.

$\overline{8}$

密萦

焉

ó

สี

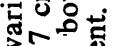

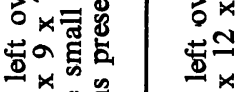

포으응

过

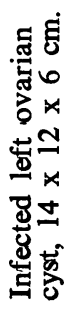

สี.

家察

.

需

蛞

\$

8

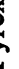

s

20

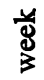

.

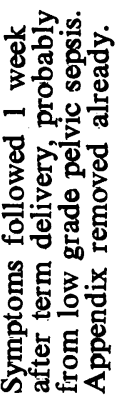

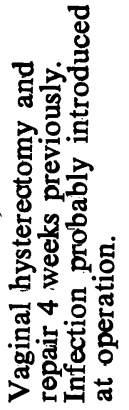

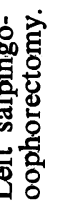

.

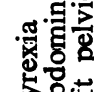

䗆苞

n
零

.]ే

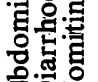

《a>

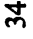

6
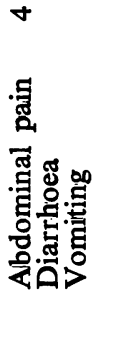

蕓

$\therefore$

ล

$\infty$
प4

욜

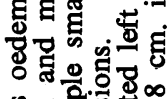

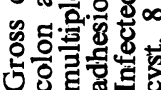

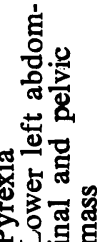

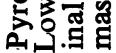

\%

กิ

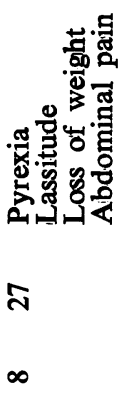

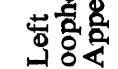

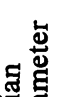

衰尔

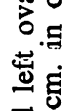

岁

$\frac{5}{8}$

敢

함

$-$

몀

ह

需最

กี

$a$

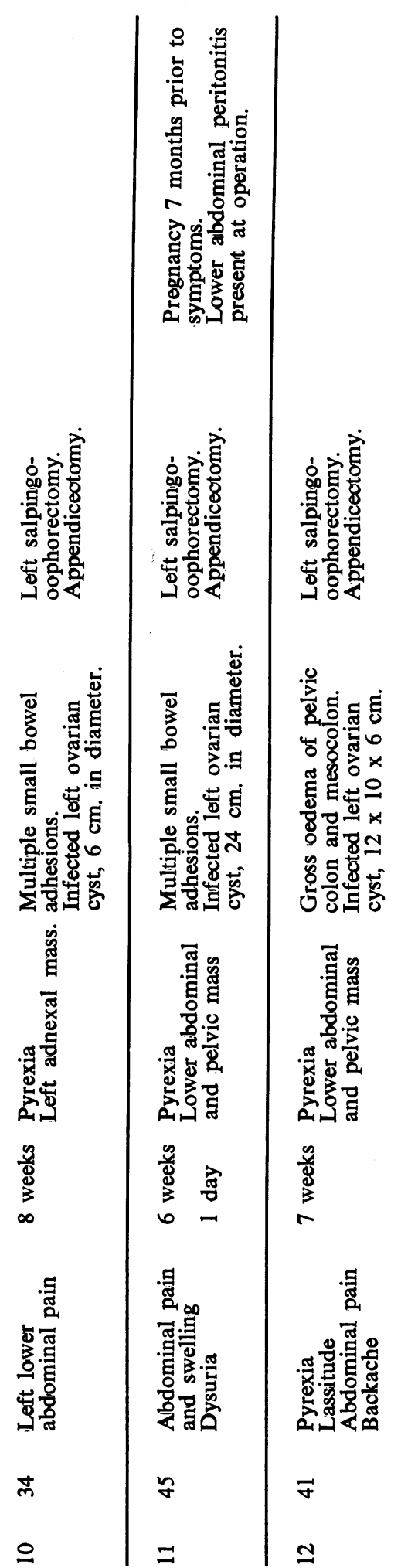

$\simeq$
离

市

c

$\overrightarrow{\bar{B}}$

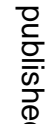

œ

$\overrightarrow{0}$

$\overrightarrow{\vec{\omega}}$

을

N

\&)

ம

윽

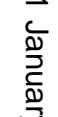

융

훙융

焉

\%ั)

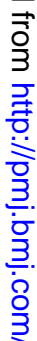

욱

음

N

N

ए్

$\stackrel{\circ}{\mathbb{D}}$

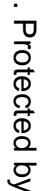


TABLE 2

INITIAL TOTAL WHITE CELL COUNT

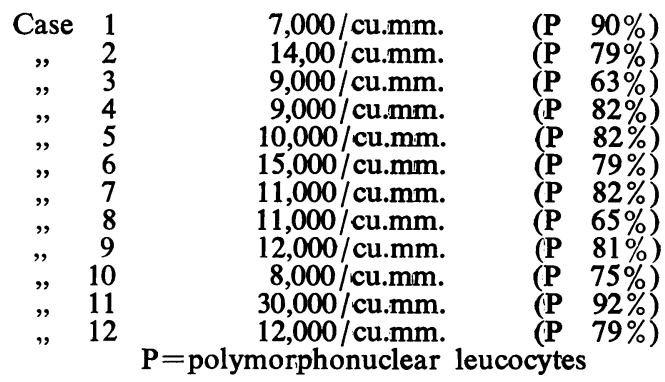

TABLE 3

\section{BACTERIOLOGICAL FINDINGS}

$\begin{array}{crl}\text { Case } & 1 & \text { Anaerobic Streptococcus } \\ , & 2 & \text { Anaerobic Streptococcus; Proteus } \\ , & 3 & \text { Staphylococcus albus; Diphtheroids } \\ , & 4 & \text { Staphylococcus pyogenes } \\ , & 5 & \text { Streptococcus faecalis } \\ \# & 6 & \text { No growth on culture } \\ , & 7 & \text { Esch. coli } \\ , & 8 & \text { Staphylococcus albus } \\ , & 9 & \text { Proteus; Diphtheroids } \\ , & 10 & \text { No growth on culture } \\ , & 11 & \text { Clostridium welchii } \\ , & 12 & \beta \text {-haemolytic streptococcus }\end{array}$

\section{TABLE 4}

\section{HISTO-PATHOLOGICAL FINDINGS}

CASE 1. Ovarian cyst, $12 \mathrm{~cm}$. in diameter, full of offensive pus. The cyst wall is thick, hyperaemic and lined $ᄋ$ by fibrinous exudate. Microscopically there is a wide zone of granulation tissue covered by an inner $\triangle$ layer of fibrin. The appendix shows enlargement of lymphoid follicles with lymphocytic infiltration of the serosa and dilation of serous lymphatics. The left tube shows oedema only.

CASE 2. Ovarian cyst, $8 \times 6 \times 6 \mathrm{~cm}$., with a thick fleshy wall, the latter being composed of thick connective tissue with numerous proliferative fibroblasts. The lining is composed of necrotic fibrin infiltrated with polymorphs. The tube is oedematous but not acutely inflamed.

CASE 3. Ovarian cyst, $6 \mathrm{~cm}$. in diameter, with thick wall (up to $1 \mathrm{~cm}$. across), containing pus and lined $b$ fibrinous debris. Microscopically the cyst is lined by granulation tissue containing numerous large macrophages with haemosiderin. There is no surviving living tissue.

CASE 4. Large unilocular right ovarian cyst, $6 \mathrm{~cm}$. in diameter. The cyst had a thick fibrous wall, the latt being composed, microscopically, of interlacing bundles of collagen fibres. There is extensive infiltration of the wall by polymorphs, necrotic macrophages and lymphocytes, and the wall is lined by adherent and necrotic fibrin.

CASE 5. Ovarian cyst, $5 \mathrm{~cm}$. in diameter, having a thick connective tissue wall and lined by haemorrhagic $\stackrel{D}{\unrhd}$ granulation tissue. Microscopically the wall is composed of young fibrous connective tissue infiltrated by inflammatory cells. The tube is oedematous but not the site of salpingitis.

CASE 6. Ovarian cyst, $12 \times 9 \times 7 \mathrm{~cm}$., with a fleshy wall, up to $4 \mathrm{~mm}$. in thickness. The cyst wall is lined by columnar epithelium and is infiltrated by polymorphs. There is considerable non-specific inflammatory reaction in the wall. The appendix shows enlargement of lymphoid follicles.

CASE 7. Ovarian cyst, $14 \times 12 \times 6 \mathrm{~cm}$., containing thick pus. The wall is up to $0.3 \mathrm{~mm}$. thick and consists of fibrous tissue with a recognisable lining of columnar epithelium in places. There is much necrotic tissue and polymorpholeucocytic infiltration in the wall. This is an infected serous cyst. The fallopian tube shows oedema only; the right tube and the appendix are normal.

CASE 8. Ovarian cyst, $8 \mathrm{~cm}$. in diameter, filled with pus. There is a mass $2 \mathrm{~cm}$. in diameter from which hairs project. The cyst wall measures $5 \mathrm{~mm}$. in thickness. Microscopically this is a benign ovarian teratoma with connective tissue, hair follicles, neuroglia, and the wall shows chronic inflammatory change. The left tube shows oedema only.

CASE 9. Ovarian cyst, $6 \mathrm{~cm}$. in diameter. The wall is oedematous and shows acute inflammatory reaction. Fragments of papillary appearance indicate that this is an infected serous cystadenoma. There is marked inflammatory reaction throughout. The fallopian tube shows cedema only.

CASE 10. Ovarian cyst, $6 \times 4 \mathrm{~cm}$., with a thickened wall and containing pus. Microscopically this is a benign teratoma showing acute inflammatory changes in the wall.

CASE 11. Ovarian cyst, $24 \mathrm{~cm}$. in diameter, with a wall $0.5 \mathrm{~cm}$. thick containing foul-smelling material. Histologically the cyst shows chronic inflammatory reaction with moderately severe necrosis of the inner layer which makes histological identification impossible. The associated tube shows serosal inflammatory change.

CASE 12. Ovarian cyst, opened, measuring $12 \times 10 \times 6 \mathrm{~cm}$. The inner wall is brown in colour. The $\stackrel{\infty}{\circ}$ fallopian tube is attached to the outer wall of the cyst and is greatly enlarged, congested and oedematous. Histologically the ovarian cyst shows a sub-acute inflammatory reaction with large numbers of plasma cells. The tubal wall is oedematous and congested and shows infiltration by polymorphs. The appendix shows serosal inflammatory reaction only. 
than another. Novak (1961) states that dermoid cysts appear more prone to infection than do cystadenomata, possibly because of the irritating character of the contents and that such cysts, because of their weight, are more liable to circulatory disturbance. It may however be that the cyst contents of the benign teratoma are more easily identifiable even where infection has been present and that the increased liability of this tumour to infection is more apparent than real.

Distinct from both the infected ovarian cyst and the tubo-ovarian abscess is the ovarian abscess in which the normal ovary becomes acutely inflamed. This condition has been well described by Black (1936) and Willson and Black (1964). The latter authors note that the condition almost always follows vaginal flastic surgery; such cases are presumed to result from the spread of infection from the ovarian pedicles. However, in none of the cases described by these authors was there infection of an ovarian cyst.

Symptoms in the case of the infected ovarian cyst will be similar to those of acute pelvic inflammation, namely abdominal pain, pyrexia and general malaise. Should the cyst be palpable abdominally, local tenderness in addition to the general symptoms will suggest infection, although it must be remembered that similar findings may be present in malignant ovarian disease in the absence of infection. The duration of symptoms is variable. In the present series, the cases have fallen into two categories. In the first (cases 2, 3, 4, 5, 6, 7 and 9), symptoms were of short duration and diagnosis was not long delayed. In the second (cases 1, 8, 10, 11 and 12), symptoms were of longer duration, were often of a general nature (loss of weight, lassitude, anorexia and pyrexia) and were associated with considerable peritoneal reaction and bowel adhesion. Examination of the latter group showed the presence of a large fixed abdominal or pelvic mass and suggested that malignant disease was present, the true nature of the condition only being established at the time of operation.

There would therefore appear to be no particular features which will help to differentiate the infected ovarian cyst from other forms of pelvic infection. Points which may aid in diagnosis are the length and general nature of symptoms in association with a unilateral tender lower abdominal or pelvic mass and these findings should ensure that the question of infection of an ovarian cyst is included in the list of differential diagnoses.

\section{Summary}

The clinical features and pathological details of a series of 12 cases of infected ovarian cyst encountered in 775 consecutive admissions with ovarian tumour are presented.

I would like to thank my colleagues in the Department of Obstetrics and Gynaecology for permission to include in this series those cases admitted under their care. I am grateful to Dr. E. C. Lewis of Redhill, Surrey for referring case 8 , to Dr. M. O. Skelton for the histo-pathological details and to Miss G. M. Pentelow, Librarian of the Royal College of Obstetricians and Gynaecologists, for her help with the references.

\section{REFERENCES}

Baydoun, A. B., and SARram, M. (1961): Ovarian Abscess in Pregnancy, Obstet. and Gynec., 18, 739. BLACK, W. T. (1936): Abscess of the Ovary, Amer. J. Obstet. Gynec., 31, 487

BoJESEN, A. (1932): Ovarian Cyst Infected with Bacillus Paratyphosus B, Ugeskr. Laeg., 94. 734.

BretTauer. J. (1908): Acute Gonorrheic Infection of a Large Ovarian Cyst, Trans. N.Y. obstet. Soc., 45-47.

Burger, P. (1925): A propos de quelques Cas de Kyste Ovarien Infecté, Gynécologie., 24, 364.

CoE, H. C. (1906): Infection of Ovarian Cystomata, Surg. Gynec. Obstet., 3, 410.

Corscaden, J. A. (1923): A Case of Paratyphoid Beta Bacillus Infection of an Ovarian Cyst, Amer. J. Obstet. Gynec., 5, 545.

Cumston, C. G. (1899): Septic Infection of Ovarian Cystoma, Trans. Amer. Ass. Obstet. Gynec., 11, 93.

Forgue, E., and Chauvin, E. (1919): La Tuberculose des Kystes de l'Ovaire, Rev. Chir. (Paris), 57, 881.

LEWIS, M. J., and LECONTE, R. G. (1902): Infection of Ovarian Cysts during Typhoid Fever; Report of Two Cases; Operation, Relapse, Recovery, Amer. J. med. Sci. n.s., 124, 590 .

Novak, E. R., and Jones, G. S. (1961): Novak's Textbook of Gynecology, Baltimore: Williams and Wilkins.

Petersen, R. (1902): Infected Ovarian Cysts, Amer. J. Obstet. Dis. Wom., 45, 802.

STAEMmLer, H. J. (1950): Uber die Infektion von Ovarialzysten durch Typhusoder Paratyphus B Bazillen nebst einem Kasuistischen Beitrag, Geburtsh. u. Frauenheilk., 10, 341.

SutToN, Sir J. B. (1913): A Note on Typhoid Infection of Ovarian Cysts, Universal Med. Rec., Lond., 3, 385.

TAYLOR, F. E. (1907): Typhoid Infection of Ovarian Cysts, J. Obstet. Gynaec. Brit. Emp., 12, 367.

WALKER, E. (1902): Infection of an Ovarian Cyst by the Typhoid Bacillus, Amer. Practit. News., 33, 420.

Watkins, T. J. (1902): Ovarian Cyst Complicated with Infection by the Pneumococcus and Staphylococcus Albus, Amer. J. Obstet. Dis. Wom., 46, 401.

Willson, J. R., and BLACK, J. R. (1964): Ovarian Abscess, Amer. J. Obstet. Gynec., 90, 34. 